By RAYNARD C. SWANK

\title{
University of Oregon's Audio-Visual Service
}

Dr. Swank, formerly librarian of the University of Oregon, is now director, Stanford University Libraries.

T September 1946, the University of 1 Oregon established a centralized, campus wide audio-visual service, somewhat experimentally, as part of the university library. This article defines the scope of this department, states the principles that guided its inception and development, describes its facilities, services, staff, and organization, and characterizes its use by the instructional departments of the university.

Scope

Audio-visual service is extended to all departments of the university. While it is oriented primarily toward the instructional and research programs, athletics and student activities are also accommodated. Offcampus extension service is not offered, since it is a function of the Department of Visual Instruction at Oregon State College.

The audio-visual fields covered by the department include moving picture films, film strips and slides, microfilms, and sound recording and amplification. Within these fields instructional and research materials are acquired or produced, cataloged, and loaned to students and faculty, and the equipment required for their use is made available. Photostating and most photo-

1 Paper read by Don L. Hunter, director of AudioVisual Department, University of Oregon Library, at Conference of Oregon Library Association, Reed College, May 27, 1948 (slightly abridged). graphic work on other than $35 \mathrm{~mm}$. film are performed by the university's photographic bureau, which is concerned primarily with publicity and pictures for the student annual. Maps, charts, prints, models, and museum objects are still handled by conventional library and museum methods.

\section{Principles}

The faculty members Lester Beck (psychology), Carl Johnson (foreign languages), and Hugh Wood (education), who proposed the organization of this department, and the library staff members who brought it into being were guided by four major principles: ( I) that ali audio-visual equipment and materials ${ }^{2}$ which are the property of the university should be placed under the custody of a centralized agency serving all departments of the university, (2) that this agency should be the existing library in order that the acquisition, organization, and use of the audio-visual and printed materials might be readily correlated, (3) that audio-visual services to instructional departments should be financed by the direct allotment of university funds to the library, and (4) that the service program should promote individual as well as group study of audio-visual materials.

The centralization of responsibility for audio-visual equipment, materials, and

2 Throughout this paper, "materials" will mean instructional materials, such as films, slides, and recordings; "equipment" will mean projectors, screens, record players, etc. 
services is a principle which, being already well established, needs little exposition. Projectors, films, and recordings, have manifold uses in many departments of the university. When in constant use, equipment or collections of materials can be deposited in the instructional departments. When needed occasionally, they can be borrowed from the central pool. Equally important is the provision in a centralized agency of an expert staff to keep abreast of developments in this rapidly changing field, advise the faculty about new equipment and instructional materials, select and purchase new equipment, keep it in repair, and instruct faculty and students in its operation.

The second principle, that this central agency should be the library, is less well established. Whatever is unique about Oregon's audio-visual program derives from the conviction that audio-visual and book services should be correlated in a single library program.

The usual arguments against library participation were considered: that the methods and philosophy of audio-visual instruction are different from instruction through books and are not understood by librarians; that audio-visual education is a specialized field with its own materials, problems, and objectives; that the library is not equipped or staffed to care adequately for the materials and equipment from a technical point of view; and that the importance of the audio-visual field justifies independent status parallel to the library.

On the other hand, it was strongly argued that audio-visual aids ought not be viewed in opposition to printed aids but should be integrated with them. Both are instructional aids used together in the same educational process, and if properly related, supplement each other. When administered with vision and a clear understanding of educational objectives, their combination in the library should result not in the neglect of audio-visual service but in a broader and more adequate philosophy of the library itself-a philosophy involving both types of aids in new relationships.

That the existing library was not staffed or equipped to handle audio-visual materials was granted, but the conclusion drawn from that fact was not that these materials be handled elsewhere, but that something should be done about the library. The necessary new staff and facilities should be provided and the old staff educated to its new responsibilities. And since the acquisition, cataloging, reference use, and circulation of instructional materials are jobs with which the library already has a wealth of experience and for which an elaborate organization already exists, it was believed that the adaptation of this agency for audiovisual purposes could be accomplished more effectively and economically than the establishment of an entirely new agency.

The decision to administer audio-visual services through the library was further supported by the conviction that, in the long view, their contribution to instruction, and especially, to research will depend less upon the manipulation of mechanical devices in the classroom than upon the systematic acquisition and organization of audio-visual resources for instruction and research-that is, upon the creation of an audio-visual library in the literal, accepted sense. Projectors, reading machines, phonographs, and recorders are merely the mechanical appurtenances of the audio-visual library.

The third principle, that audio-visual services to instructional departments should be financed by the direct allotment of university funds to the library, was readily accepted as soon as those services were recognized as a legitimate extension of the traditional library function. The traditional library is an all-campus agency which, although in one sense the servant of the 
instructional departments, is expected to make a contribution of its own to instruction and research. Similarly, the audiovisual library was conceived as an integral part of the educational program. Teaching with films and phonograph records was given the same status as teaching with books. In addition to enabling the audio-visual department to accept an educational responsibility, the direct allotment of university funds obviates the undesirable red tape which accompanies interdepartmental budget transfers.

Fourth, as plans for the audio-visual department took shape, the conviction grew that in the long run the individual study of films, slides, recordings, and related materials would become as important to instruction, certainly to research, as their group use by entire classes and other large audiences. If the proper facilities for individual study were available, a faculty member would often have no better justification for showing films in the classroom than for reading aloud from textbooks which students can read for themselves at the library.

The provision in libraries, moreover, of auditoriums and other large rooms for audio-visual purposes was felt to offer less than that of a number of small record booths, slide and film projection rooms, and the like. While facilities for record concerts and movie programs for students are obviously desirable, they should not displace the less dramatic type of quarters to which students can take class assignments for private intensive study.

\section{Facilities}

Temporary quarters were found for the new department on the ground floor of the library building next to the newspaper reading room. These include an office and a shop in which equipment is stored and repaired and films are previewed. Three small adjacent rooms, originally intended for reading to blind students, are used interchangeably for microfilm reading, listening to recordings, rehearsing speech and language exercises with wire and tape recorders, and projecting slides. A photographic laboratory, equipped for microfilming, slide making, and the processing of both blackwhite and color film, is located nearby. On the third floor of the building is the Douglass room, containing the record collections (soon to include tape as well as disc), nonmusic as well as music, phonographs for both individual and group listening, and music scores. The library's browsing room contains a phonograph for record concerts of a recreational character and can be darkened for the projection of moving pictures and slides. Selected classrooms, lecture halls, and such specialized rooms as speech and music studies are being equipped as rapidly as possible with blinds, sound absorbing materials, screens, or whatever is required to facilitate the use of audiovisual methods. There being no suitable space in the library building, a disc recording studio is still maintained at the school of music.

These temporary arrangements are soon to be replaced by new quarters in the library addition upon which construction is scheduled to begin late in 1948. There will be a reception room with space for audio-visual magazines, catalogs, bibliographies, and other reference tools. Adjoining will be the director's office, shop and storage areas. Two combination recording and film projection studios are planned with a common control room. The new Douglass room will contain shelving for disc and tape recordings and music scores, table-mounted phonographs with earphones, a series of phonograph booths, a group listening room, and a small piano room in which students can try out music scores. The phonograph booths will also double as wire and tape recording booths for language, speech, music 
and other students, and as slide projection booths. Several larger booths will also be provided especially for slide and film projection. Space for photographic processes will include dark rooms and a studio for microfilm, copy, and other camera equipment. Conference and seminar rooms in the subject departments of the library (humanities, sciences, etc.) will be equipped for use of phonographs, films, and slides. Microfilms will probably be stored and used primarily in the department of special collections (rare book, archives, and Northwest history). Facilities outside the main department will continue to be developed on the theory that, beyond a certain point in the growth of the program, it will prove desirable to decentralize further the use of audio-visual materials through integration, on the one hand, with the subject departments of the library and, on the other hand, through controlled distribution to speech, music, psychology, language, art, and other instructional departments in which use is intensive.

The use of audio-visual materials is, of course, decentralized now to a considerable degree; the central department serves primarily as headquarters for the acquisition, production, organization, repair, and distribution of materials and equipment. A brief account of the nature and disposition of present equipment and instructional materials will elucidate this point.

The film collection is still small and growing slowly because (I) instructional films worth buying in a number of subjects at college level are not available, (2) many good films are needed only occasionally, perhaps only once a year, for single classes, and should therefore be rented, and (3) the department of visual instruction at Oregon State College maintains a large extension collection which the university uses and does not wish to duplicate. Present policy is to store all films in the audio-visual department. The filmstrip collection is also still small and stored in the audo-visual department. Both films and filmstrips are loaned to or deposited in the instructional departments as needed.

The slide collections, now totaling about 25,000 slides, are stored almost entirely in departmental deposits. The audio-visual department is only now starting a collection in the main library for departments which do not care to house the slides in their subjects and for little-used slides being returned from deposit. Future policy will probably encourage the weeding of departmental deposits, the return of inactive materials to a central repository, and the free interchange of little-used materials between the deposit collections and the central repository.

Disc recordings, including transcriptions of both musical and nonmusical subjects, are now centralized in the Douglass room, with the exception that small and fluid working collections are deposited in the school of music and the school of physical education. The physical education deposit consists primarily of folk dances. A growing collection of tape recordings, now kept in the audio-visual office, will be moved to the Douglass room as soon as separate tape players are available. No recordings are yet being preserved on wire because of the high cost of wire cartridges. Both disc and tape recordings are loaned to faculty members for classroom and other instructional purposes.

All audio-visual equipment belonging to the university, except a few pieces which could not easily be shaken loose from their original departmental owners when the central service was established, is now under the custody of the audio-visual department. A major part is on deposit in various instructional departments where use is so frequent that borrowing from the library is impractical. The rest is held in a central pool for general campus use.

Four sound and two silent moving pic- 
ture projectors are now in the central pool. Three additional projectors are located in the university high school, military department, and athletics department. Twentytwo slide projectors of various types, including combination slide and filmstrip projectors, are available. Of these, seven are pooled and fifteen deposited in the anthropology, architecture, geology, education, physics, biology, and chemistry departments. There are four opaque projectors of which two are deposited in the music and architecture departments. Six portable, dual-speed transcription or record players are on hand, two of these being deposited in the music and physical education departments. A large console phonograph is located in the Douglass room and a combination radio-phonograph in the browsing room. Twelve table-mounted phonographs with earphones are located in the Douglass room. Five wire recorders are on deposit in the speech, music, and foreign language departments, and two tape recorders are pooled. One console disc recorder is in the music department, one portable in the speech department, and one portable is pooled. Camera equipment includes a Graphlex microfilming outfit (used also for slide making), a $16 \mathrm{~mm}$. moving picture camera, and $35 \mathrm{~mm}$. miniature cameras. There are three microfilm readers, one of these on deposit in the history department. Sound reinforcement equipment includes four amplifiers of different types and a variety of microphones and speakers. Miscellaneous items include a number of screens, both pooled and on deposit, film splicer, vacuum tube voltohmeter, light meters, film developing tanks, enlarger, etc. An ozalid machine is available at the registrar's office.

\section{Services}

The services normally rendered by the audio-visual department may now be enumerated.
Information. The director tries to keep abreast of developments in equipment and instructional materials and to inform the faculty of those pertinent to their fields of interest. He actively stimulates the wider and more effective use of audio-visual techniques by suggesting and demonstrating new possibilities to faculty members. $\mathrm{He}$ offers bibliographical and reference assistance and aids in the evaluation of instructional materials.

Acquisition. The department reviews requests for equipment and instructional materials and approves all requisitions for the entire campus. It therefore bears central responsibility for the selection of appropriate equipment, for the elimination of unnecessary duplications, and for the building of the university's resources in films, recordings, etc. Film, filmstrip, and slide rentals for all departments are also handled by the audio-visual department. During January and February 1948, film rentals totaled 48 and 85 respectively.

Production. The university's audiovisual resources are augmented not only through the acquisition of materials from outside sources, but also through local production. All such materials produced by the audio-visual department for instructional purposes are paid for by the library and added to the library's collections. During January and February, IOI4 slides, a large part in color, were made; 755 frames of microfilm were taken; and 626 ozalid prints were produced. Disc, wire, and tape recordings are made of a wide range of subjects, from concerts and public addresses to counseling interviews and programs for radio broadcast. Some of these are ephemeral; other are cataloged and preserved for archival or instructional purposes. Worn, irreplaceable disc recordings are copied, sometimes on tape, and wire or tape recordings are often copied on discs for more convenient usage. The audio-visual department helped prepare the pilot version of the 
educational film, "Human Growth," sponsored and distributed by the E. C. Brown Trust of the University of Oregon.

Circulation. Equipment and instructional materials are, of course, loaned to faculty and advanced students and deposited when necessary in departmental offices and classrooms. Incomplete records for January 1948, which was not a peak month, show that moving picture projectors were used at least 42 times, slide projectors at least 182 times, portable record players 112 times, sound amplifiers 9 times, tape recorders 128 times, and wire recorders 160 times. Delivery and pickup service is provided by the audio-visual department, although faculty members are encouraged to call for their own materials whenever possible.

Operation of Equipment. Trained operators, usually students, are supplied by the audio-visual department when the nature of the job requires them or when it is clear that a department cannot provide competent operators from its own staff. The general policy, however, is to train, as an important part of the educational process, as many faculty members, graduate assistants, and students as possible to operate their own equipment. Thus in February only 66 hours of operator service were provided to the instructional departments by the central service. No charge was made for this time.

Instruction. In addition to giving informal instruction in the operation of equipment, to advising faculty of new developments in the audio-visual field, and to helping faculty and students select appropriate materials for their purposes, the director also assists with formally organized courses involving the instruction of students in the use of audio-visual materials. An example is the course in audio-visual aids offered by the school of education.

Design and Repair of Equipment. The audio-visual department is responsible for keeping all equipment in adjustment and repair. Pieces on deposit in the instructional departments, as well as those loaned from the central pool, are regularly checked and serviced. Beyond this, the department is often engaged in the designing of new equipment and the adaptation of old equipment for new purposes. The table-mounted phonographs in the Douglass room, for example, were designed and assembled by the audio-visual staff; and experiments are now being conducted toward the development of a "loop" recorder in which one minute or so of tape can be run continuously through the erasing and recording heads.

Noninstructional Services. Sound amplification and other services are provided for athletic events, convocations, conferences, dances, and the like. These services, unlike those in instructional departments, are paid for by the departments or organizations requesting them, and the money so collected is used to pay the operators and buy equipment of the kinds required for these jobs. The educational activities board finances for students a weekly "movie night" which is now managed by the audio-visual department. A subcommittee of the faculty library committee assists with the selection of films to be included in these programs.

\section{Staff}

The staff of the audio-visual department consists at present of the director, his secretary, a music librarian (half-time), a technician, and student assistants.

The director, Don L. Hunter, is a regular department head of the library with rank of assistant professor. $\mathrm{He}$ attends all department head meetings, is a member of the library staff association, and is active in staff affairs, both professional and social. He has a bachelor's degree in electrical engineering and has specialized in sound recording and reinforcement. He originally became interested in photography as a 
hobby. He has no professional library training.

The music librarian, True Morris, who supervises the Douglass room, is a professionally trained librarian with a masters degree in music. Her academic rank is instructor. Half her time is spent as a member of the reference staff.

The technician, Robert Merrell, is classed as audio-visual assistant in the Oregon state civil service. He received his training in the audio-visual field while a member of the armed forces. Before joining the library staff, he served as a radio technician for $\mathrm{KOAC}$, a state-owned station located at Corvallis.

Student assistants are used as equipment operators, for delivery and pickup service, and for attending the Douglass room.

As will be noted later, other members of the library staff participate in the work of the audio-visual department, since all orders for films and recordings are handled by the acquisition department and all acquisitions are cataloged by the catalog department. The library-trained staff is teaching the audio-visual staff as rapidly as possible what it needs to know about library methods, and the audio-visual staff is teaching the librarytrained staff what it needs to know about audio-visual methods.

\section{Financial Administration}

According to the principle already stated, the audio-visual department is financed by direct allotment of university funds to the library. These allotments are incorporated into the general library budget. No funds are budgeted to the instructional departments by the president for audio-visual purposes.

The final budget breakdown for the general library includes separate accounts for audio-visual wages, audio-visual supplies, film rentals, general audio-visual materials, and departmental audio-visual allotments. "Film rentals" cover rentals for all instructional purposes. Funds for the purchase of instructional materials (films, recordings, slides, etc.) are divided between "general audio-visual materials" and "departmental audio-visual allotments." The former is used by the director for the purchase of materials of general interest and for helping out departments whose allotments prove to be inadequate. The latter consists of allotments, analogous to the traditional allotments of book funds, placed at the disposal of the instructional departments. These allotments are assigned on the basis of need by the head librarian, in consultation with the director of the audio-visual department, the acquisition librarian, and the faculty library committee. It is expected that the departmental book and audio-visual allotments will soon be consolidated.

Audio-visual equipment and travel have not been separated in the budget from general library equipment and travel. Funds collected for services to noninstructional departments are credited to a special audio-visual account which is separate from the main library account.

\section{Acquisition and Cataloging}

The library is the university's purchasing agent for films, slides, recording, and other instructional materials. Orders are placed and the materials received by the acquisition department, which controls the funds for the purchase of audio-visual materials as well as books and which exercises final approval on all orders. Orders for supplies and equipment are placed by the librarian through the university's business office.

Audio-visual materials, those produced by the audio-visual department as well as purchased through the acquisition department, are then cataloged and classified by the catalog department. Cards for films, filmstrips, and recordings (tape as well as 
disc) are made for the general public catalog and others for separate catalogs in the audiovisual department. In the general public catalog, a recorded speech by Theodore Roosevelt is therefore listed among his printed works, and a film on sound waves is listed among printed works on the same subject. Cards for slides are not being filed in the general public catalog, although the compilation of a central card catalog of slides in all the university's collections is in progress. Ozalid contact prints made from the mounted slides or from the film strips before cutting and mounting are pasted on the catalog cards to facilitate identification and selection.

Slide classifications with a uniform base for all subject fields are being developed in order to permit the exchange of slides among departmental deposits and the central repository as educational needs change. Slides, like books, are expensive; and the same slides are often useful to several departments. Anthropology, biology, and geography, for example, have common use of many slides; and the collections in art and architecture are useful to foreign languages, anthropology, history, and music. No subject classification is applied to films, filmstrips, recordings, or microfilms, these being arranged simply by physical type, size, and order of acquisition. Recordings, however, are divided into several very broad classes, such as music as well as by size.

Use

Although a few statistics suggesting amount of use have been given under the heading Services, the kinds of use made of the audio-visual department by selected instructional departments may now be characterized.

The school of music regularly sends its students to study recordings and scores in the Douglass room. Students in music theory, history and appreciation, and con- ducting are enabled to carry out individual assignments so far without scheduling the use of phonograph equipment. Recordings are extensively borrowed for classroom use, and a record deposit is maintained in the music building. A portable record player is on deposit there for classroom use. Also on deposit is a wire recorder which is constantly used to record student and faculty practice, both instrumental and vocal. More permanent records of student progress are made on discs. The audiovisual staff advises the music staff in the effective use of recording equipment and operates the equipment for them when superior results are desired. The audiovisual staff now records, usually on tape, many concerts and recitals. These recordings enable the performers to rehear their work and often comprise valuable additions to the cataloged record collections in the Douglass room. A recent festival of modern music, for example, yielded several recordings by outstanding composers of their own works and recordings of a number of other pieces not commercially available. Such recordings, and sometimes those of faculty and student recitals, are incorporated from time to time into the daily browsing room record concerts. Slides and filmstrips of music scores are produced by the audio-visual department for use in music classes.

The department of foreign languages sends its students to the Douglass room to hear songs in Spanish, French, and other languages. Recordings of this type are also borrowed, together with a portable player, for classroom use. Students are assigned to practice pronunciation with Linguaphone and similar recordings and with tape or wire recorders in the three booths in the audio-visual department. A wire recorder is on deposit in the department of foreign languages for practice and teaching purposes. Additional recorders are 
borrowed to record oral examinations. Numerous foreign language films are rented, and some are incorporated into the "movie night" programs managed by the audio-visual department. Slides are used in some classes as background material. Some of these are made especially for this purpose by the audio-visual department, others are borrowed from the collection in the school of architecture and allied arts.

The school of architecture and allied arts has the largest slide program of all departments on the campus. Large numbers of slides, mostly copied in color from illustrated books, some original pictures of buildings, gardens, art objects, etc., are made by the audio-visual department for their rapidly growing collection. Student work is preserved on film, the better examples being made into slides for instructional purposes. The use of slide projectors is very heavy. Films on techniques of painting, drawing, pottery making, and the like are frequently rented; a few are purchased. Preliminary work is under way on the production of technique films. Such films as "The River" are sometimes used for background material in survey courses. Music records illustrating art movements are used for background in history courses. The audiovisual department records special lectures now and then for playing to interested classes.

The speech-drama department (including radio) is another heavy user of audio-visual services. Wire recorders are regularly on deposit in the department for use in speech practice and teaching, and in speech correction. One of these is also used by the veterans counseling bureau. Students of speech study recorded speeches and dialect recordings. Recordings of these types are also loaned for classroom use. Slides of speech organs are used in speech correction work. Drama students use the Douglass room for study of recorded plays and dia- lects. Slides of stage settings and lighting equipment are used in classrooms. In connection with play productions, the audiovisual staff makes special recordings for sound effects and musical backgrounds. Tape recordings are used to study audience reactions. Sound reinforcement is supplied for large play productions in McArthur court (used as an auditorium). In the little theatre, the audio-visual staff is installing wiring for speakers in the dressing rooms for cueing purposes. Maintenance of equipment in the radio studios is a responsibility of the audio-visual department. Tape recordings are made and music recordings loaned for radio broadcasts.

Anthropology requires many slides and films and uses tape to record field notes. Education uses the audio-visual equipment as teaching materials in audio-visual courses, and previews numerous films at the elementary and secondary school levels. Ozalid prints of city maps are made for students in sociology. The library's department of special collections benefits from the microfilming, ozalid, and slide services.

\section{The Northwest}

Although the work of the audio-visual department has progressed little further than the provision of "instructional aids" in the usual limited sense, the department is conceived to have a broader, longer range objective-that of collecting, producing, and preserving audio-visual documents significant to historical and sociological research, especially on the Northwest. It is hoped that a beginning can soon be made toward the systematic documentation of the current local scene. An unexpected wedding of interests between the department of special collections, which is actively acquiring early Western photographs for historical purposes, and the audio-visual department is leading toward the organi-

(Continued on page 310 ) 


\section{Record Library}

Three record players will be available, and though wire does supersede the record in many respects, the latter will be a large item in the program. The college owns a record library of many rare musical records, and is in the process of adding recent releases of musical recordings. One benefactor has presented the library with several records of considerable value. Represented in the record library will be examples of good speech, literature, and historical speeches which have been made by persons who are involved in the major world issues.

In connection with the record library, there will be many occasions when students and faculty may listen together to the great artists who have recorded the best in musical literature. These gatherings are informal, the only requirement being an interest in good music. During the appropriate seasons, this group will come together to hear the broadcasts of the Metropolitan Opera and New York Philharmonic Symphony Orchestra.

The last item in the original program is the public address system which will be used in the gymnasium, chapel, athletic field, and other places where there are large assemblies. This outfit consists of two indcor speakers, two outdoor speakers, and a control box which carries both a microphone and a record changer. This equipment is to be used for athletic events, dances, assemblies, and other all-collegiate functions.

Our audio-visual program will be under constant examination, study, and evaluation and it is the intention of the college staff to develop its maximum values in the whole pattern of the educational process.

\section{University of Oregon's Audio-Visual Service}

\section{(Continued from page 307)}

zation of field trips designed to produce for the future historian both audio and visual records of Oregon industries, peoples, institutions, and folk arts and customs. A committee of faculty members representing the anthropology, history, business, music, and other departments, as well as the library, has been appointed by the president to plan and help execute field trips of this kind. Consideration is being given to such projects as the sampling of local church services, city council meetings, lumbering activities, and such cultural groups as the Basques in Eastern Oregon.

\section{Conclusion}

As stated earlier, whatever is unique about the University of Oregon's audio- visual department derives largely from the effort to correlate the acquisition, organization, and use of audio, visual, and printed resources under the administration of the university librarian. The effort is frankly experimental, and its success or failure should be significant not only to librarians but also to audio-visual specialists and university administrators. The faculty attitude, with very few exceptions, has been warm even when departmental equipment was being transferred to the custody of the library. The library staff has been cooperative and eager to learn. If the experiment succeeds, the practicability of a fully correlated audio-visual and book service on a university campus will have been demonstrated. 